\title{
Etic and Emic Orientations on Cultural Intelligence of Global Professionals Under Belt \& Road Initiative
}

\author{
Ying Zhang \\ 1. International Business School \\ Yunnan University of Finance and Economics \\ Kunming, China \\ 2. School of Management and Marketing \\ Charles Sturt University, Australia \\ angie@ynufe.edu.cn \\ Yunwu $\mathrm{He}^{*}$ \\ Shenzhen Tagen Group Co., Ltd \\ Shenzhen, China \\ 1170660350@qq.com
}

\author{
Jianchun Zhao \\ Baqian Lawfirm Yunnan \\ China \\ 825496414@qq.com
}

Yaqin $\mathrm{Lu}$

Economic Research Institute

Yunnan University of Finance and Economics

Kunming, China

luyaqinhuan@126.com

\begin{abstract}
This paper conceptualizes the Etic and Emic Orientations on Cultural Intelligence. The implications justify the importance of understanding the role of becoming global professionals under the Belt \& Road Initiative. By identifying the individual differences in cultural intelligence and understanding Etic and Emic Orientations between the east and west is critical for better individual performance in cross-cultural transitions for the purpose of effective international assignments along the
\end{abstract} Belt \& Road countries.

Keywords: cultural intelligence, Etic, Emic, individual performance, international assignments

\section{I.INTRODUCTION}

Despite of the recent rise of anti-globalist movements in various parts of Europe, the America and Asia, globalization has not been largely interrupted. The "global village" can hardly be broken by protectionist and nationalistic policies, which has been evidenced by the continuing increase of the flow of products, capital, employees, and information. This trend has contributed to rapid increases in workforce mobility in the last decade, and is unlikely to abate in the foreseeable future. Global transition of professionals is a difficult and costly exercise if not carried out successfully. Asia under the Belt \& Road Initiative represents the fastest growing economic region in the world both in terms of nominal Gross Domestic Product (GDP) and Purchasing Power Parity (PPP) according to many reliable sources such as the World Bank and the International Monetary Fund. Containing approximately $60 \%$ of the world's population in 49 nations, Asia simply cannot be overlooked by the academic and practitioner. To aid in this task, more focused research needs to be conducted such as enhancing our understanding of those professionals likely to be more successful in cross-border transitions and leadership roles, thus reducing the costs to MNC's generally in their staffing practices and improving the benefits associated with developing and enhancing strong and meaningful cross-cultural business associations as well as sound and meaningful career opportunities for individual professionals.

It is generally recognized that global professionals with higher levels of cultural intelligence are more likely to adjust at quicker rates because individuals' cultural specific

*Corresponding author 
knowledge and motivation can facilitate professionals' adjustment in the host country in various stages of socialization [1]. Given the recognition of the value of individuals with high cultural intelligence in international business, studies on cultural intelligence have increased considerably.

However, understanding how cultural intelligence, relative to its four dimensions, is a vital aspect of cross-cultural competency, in order to enrich or improve professionals' performance remains of concern. $\mathrm{Ng}$ and Earley pointed out that there were many interesting questions about cultural intelligence that remain to be asked and answered. Likewise, both Bücker and Poutsma and Bücker, Furrer and Lin have indicated that cultural intelligence construct went through sophisticated testing without a clear definition in the first place [2]. As such, it requires further exploration. The fundamental question though, is whether the four dimensions of cultural intelligence differ among nations, according to different national cultures. Indeed, the elementary question of whether cultural intelligence is culture-free or culture-bound has not been established.

The answer to this question is critical to an overall understanding of individual cultural intelligence. It is therefore crucial to provide information that can assist the practice of international human resource management. For example, international staffing and training may greatly benefit from such information by allowing the development of relevant skill profiles based upon such things as, different national cultures, different cross-cultural experiences and length of service.

\section{II.LITERATURE REVIEW}

\section{A. The Emic-etic Distinction}

Staff selection and training processes could be better focused on the respective requirements, both for global mangers and non-managers undertaking international business assignments. If cultural intelligence and individual performance relationships were culture-bound, then management might select and train employees from a culture specific perspective. On the other hand, if cultural intelligence and performance relationships were culture-general, selection and training processes could be more generalized. The purpose of this section is to evaluate psychometric data and theories regarding the controversy as to whether cultural intelligence and performance relationship is culture-free or culture-bound.

The theoretical positioning in cross-cultural research concerns the emic-etic distinction (Berry, 1997), both of which are legitimate research orientations (Dowling et al., 2008) [3]. Emic refers to culture-specific concepts and behaviours, whilst Etic refers to, culture-common concepts and behaviours. Broadly, this distinction forms two basic approaches to the study of culture and social behaviour: emic (culture-specific) and etic (culture-general) approaches (Triandis, 1994). Chan and Rossiter (2003: 1586) explained that the etic approach is concerned with "identifying universal dimensions that underlie cultural differences", whereas the emic approach holds that, "attitudes and behaviours are expressed in a unique way in each culture".

\section{B. The Convergence and Divergence Schools}

A distinction between the "convergence" school and the "divergence" school with respect to culture has also been made based on the Etic/Emic orientations. In an important early paper which reviewed the convergence/divergence debate, Child (1981) made the point that there is evidence for both convergence and divergence in that the majority of the convergence studies focus on macro level variables (e.g. Organizational structures used by firms across cultures). Whereas, the majority of the divergence studies focus on micro level variables (e.g. The behaviour of people within firms). Child (1981) concluded that while firms in different countries are becoming more alike (an Etic convergence approach), the behaviourr of individuals within these firms maintain their cultural specificity (an Emic divergence approach).

With a divergent perspective orientation, emic scholars (eg. Berry and Ward, 2006; Hall, 1976; Hofstede, 2001; Kim et al., 2006; Laurent, 1983; Trompenaars, 1997) claim that the dominant force in shaping the values, beliefs, and attitudes of manager is deeply rooted in "national core cultures", not economic ideology or technological growth. "Core cultures" are clear, robust, and stable across time, thus cultural difference cannot be leveraged and cultural competency and 
business strategy should aim to gain differentiated positions and advantages [4]. For example, Hofstede's (1980, 1991, 2001) "Onion" model of culture and Hall's (1959) cultural dimensions were firmly based on the Etic approach and divergent philosophy in that, the opposite poles of all national cultural dimensions can be either feminine or masculine, long-term or short-term oriented, individualistic or collectivistic, uncertainty-tolerant or uncertainty-anxious, authoritarian or egalitarian, monochronic or polychronic, and high-context or low-context, depending on situation, context, and time. The predisposition of Hofstede's "Onion" model is that culture is a key influencer of individual behaviour. Based on this divergent perspective, national culture should be a significant independent variable for cultural intelligence and performance relationships.

Whereas Emic divergence scholars hold that culture is a key factor influencing individual behaviour, Etic convergence scholars believe that it is behaviour itself that defines culture. An illustration of an Etic convergence approach is Fang's (2006) "Yin - Yang" conception and “Ocean" metaphor of culture (see Figure 1) [5]. Tony Fang and his colleagues, a group of more etic perspective oriented researchers, revisited the established emic view that has been long dominant in the cross-cultural academic arena for decades. Fang's (2001; 2003; 2006b; 2012) and Fang and Faure's (2011) propositions and studies, critiqued polarized theorization of cultures, or in other words, took the bipolarized theorization of cultures a step further into a bigger picture of holistic, dynamic and dialectical Yin-Yang philosophy guided cross-cultural management field [6]. The yin-yang image contains Chinese ancient wisdom in which the black and the white areas represent two opposite energies in the same universe, called yin and yang, respectively. Yin represents female elements the moon, night, water, weakness, darkness, mystery, softness, and passivity. Whereas Yang represents male elements - the sun, day, fire, strength, brightness, clearness, hardness, and activity.

\section{Cultural Intelligence}

Culture and intelligence are closely intertwined (Berry, 1974; Sternberg, 2004). For instance, attitudes and behaviors that are considered proper and intelligent in one culture may be considered as improper or a demonstration of low level intelligence in another culture. Many adjustment studies at the micro level (Ang et al., 2007; Earley, 2002) over last ten years have identified Cultural Intelligence (CQ) as a vital cross-cultural construct that determines expatriates cross-cultural adjustment process in international assignments. Expatriates with higher levels of CQ are reported to be more likely to adjust at quicker rates (Ang et al., 2007; Earley and Mosakowski, 2004).

Earley and Ang (2003: 59) advanced the concept of cultural intelligence as a basis for explaining individual differences in capability to function in intercultural settings with Cultural Intelligence referring to "a person's ability to adapt effectively to a new cultural context" [7]. Similarly, Thomas and Inkson (2003: 62) define cultural intelligence as "the capacity to interact effectively with people from different cultural backgrounds" [8]. Researchers have begun to explore the nature of cultural intelligence (Earley and Ang, 2003; Earley and Mosakowski, 2004; Thomas and Inkson, 2004). In Singapore, for example, Soon Ang has established a research centre for the study of cultural intelligence with its U.S. counterpart, the Cultural Intelligence Centre based in Michigan. The whole conceptualization of multi-dimensional CQ focuses primarily on a specific domain of intelligence, that is, intelligence in cross-cultural settings.

CQ draws from various disciplines including cross-cultural psychology, anthropology, sociology, and management. Specifically, the concept is based on several valued theories in the psychological sciences including Stryker's (1980, 1987) Identity Theory; Erez and Earley's (1993) Cultural Self-Representation Theory, Bandura's (1977a; 1977b; 1997) Social Learning Theory and self-efficacy theories, and Triandis's (1972) work on the analysis of subject culture. Cultural intelligence provides the framework for an innovative method in understanding cultural adjustment, social identity, global management, and intercultural communication (Earley \& Ang, 2003). In this sense, Cultural Intelligence is a multifaceted approach to intelligence that represents individual variability and focuses on the ability to adapt to new cultures and cultural situations.

It is a particular concern for expatriates where in not knowing what to expect; the differences encountered upon arrival and in various stages of settling in, can often result in 
culture-shock, uncertainty and disorientation associated with an unfamiliar way of work and life. Essentially, CQ is grounded in the theory of multiple intelligences (Sternberg and Detterman, 1986), and is conceptualized as a multi-facet model (Earley and Ang, 2003). [8] Earley and Masakowski (2004:141) illustrate that cultural intelligence resides in the body, the heart, and the head. Similarly, Thomas and Inkson (2003) also view cultural intelligence as having three components: (i) Knowledge, (ii) mindfulness, and (iii) a behavioural component. Earley and Ang (2003) further advanced four dimensions that constitute cultural intelligence: (i) metacognitive, (ii) cognitive, (iii) motivational, and (iv) behavioural dimensions. [8] These four dimensions of CQ reflect the existing observation of intelligence (Sternberg and Detterman, 1986) as a complex, multidimensional individual attribute and will now be described in detail[9].

\section{THEORY DEVELOPMENT}

\section{A. From Yin - Yang Perspective to Ocean Metaphor}

The Chinese traditional philosophy implies that yin and yang coexist in everything, and that everything embraces both yin and yang. There exists neither absolute yin nor absolute yang. This is denoted by the black dot in the white and the white dot in the black. Chen (2001) explains that, the opposites contained within them are the seeds of the other, and together they form a dynamic and changing unity. Fang (2001; 2003; 2006b; 2012) [10], Chen (2001) and Fang and Faure's [11] indicated that, Yin and Yang cannot survive without each other. They complement each other, they depend on each other, they exist in each other, they give birth to each other, and they succeed each other at different points in time. Yin-yang suggests that human beings, organizations, and cultures intrinsically embrace paradoxes for their sheer existence and healthy development. Fang (2006) notes the concept embraces paradoxes and holds that opposite forces exist simultaneously and accepts that opposites coexist and can reverse their positions at any given time in history[12].

Importantly, Fang (2006) created the "ocean" metaphor of culture to further picturize the theorization that Yin-Yang opposite forces coexist simultaneously and can reverse their positions at any given time in history. The ocean embraces not just visible wave patterns on its surface (compared to visible cultural values and behaviours); but also numerous ebbs and flows of amazing depth (comparable to "hibernating," unseen and unknown cultural values and behaviours). As Yin and Yang produce each other, a culture's tendency toward one extreme of a bipolar dimension (e.g., femininity) creates and fosters the opposite tendency (e.g., masculinity) within the same culture in a dynamic process of change and transformation. Simmel (1997) notes that this "both/and" perspective of culture is grounded in a dialectical and paradoxical view of universal phenomena as suggested by Yin-Yang. Fang's (2006) "Yin - Yang" perspective and "Ocean" metaphor of culture remind us that, the categories and types that we isolate from the world of phenomena we do not find there because they stare every observer in the face; on the contrary, the world is presented in a kaleidoscopic flux of paradoxes which has to be reconciled by our minds, and this means largely by the ever-changing state of universe and mutually-transforming energy of the opposite elements. It is, however, easy to dissect the dynamic system of paradoxes along lines laid down by our biased observation and exaggerate differences of cultures and the consequent barriers to intercultural understanding. We cut cultures up, organize it into concepts and ascribe significances as we do, largely because we pretermit the fact that no cultural element is wholly isolated and self-contained in the totality of culture. There are important linkages between and within all national cultures and cultural dynamics-- linkages that stem in part form diffusion, and in part from the fact that all cultures are built around biological, psychological, and social characteristics common to perceptual and other faculties of Yin-Yang duality as they influence and direct these faculties into prescribed polarized channels. Fang (2012) further conceptualizes culture as possessing inherently paradoxical value orientations, and proposes that, potential paradoxical values coexist in any culture and each culture is a unique dynamic portfolio of self-selected globally available value orientations. To direct behaviours in a particular context at a particular time, individuals select the most relevant value(s) from the full range of potential value orientations, thus in a given context at a given time some Yang nature values can be promoted in a culture, while other Yin nature values can be 
suppressed (or vice versa), thus resulting in a unique value configuration.

Based on this etic oriented assumption, culture is a product of Yin-Yang which it in turn reflects. The dynamic energy of Yin and Yang creates culture; culture is a means of Yin-Yang and a reflection of endless communication struggles and paradoxes. Yin-Yang carries culture, and culture carries the entire body of values by which we come to perceive ourselves and our place in the world. Countries liberalize their markets and world market becomes more alike in this borderless global village, the cultural interactive skills and strategic business behaviour should fit the unique dynamic portfolio of self-selected globally available value orientations.

\section{B.Culture-free vs. Culture-bound}

Empirically, the results of Graf's (2004) study in the USA and Germany reported that individual inter-cultural competencies are culture-free in the two nations. The study supplied some firsthand evidence that cross-cultural competencies were culture-general (for Western countries). However, findings from two national cultures do not allow conclusions for further nations. The significant tendency for inter-cultural competencies to be national-culture-specific or culture-bound needs to be noted. That is, culture is "not a situation-free, context-free, or time-free construct, but rather is embedded in situation, context, and time" (Fang, 2012:11). As stated by Berry and Ward (2006: 71), "because there is no culture-free behaviour, there can be no culture-free cultural intelligence", even though the cultural intelligence ground breaker Earley (2002) firmly holds that a person having high cultural intelligence is culture free [13]. Therefore, depending on the circumstances and time point, there will be greater differences in the level of Emic cultural intelligence towards specific foreign culture than Etic cultural intelligence for the same expatriate at the same given time point. Cultural intelligence towards specific foreign culture and cultural intelligence towards general all new cultures should not be regarded as the same concept, thus, our theoretical proposition in paper is drawn that there will be notable difference in the levels of cultural intelligence towards specific foreign culture (Emic cultural intelligence) and cultural intelligence towards general all new cultures (Etic cultural intelligence), such that
The levels of emic cultural intelligence will be higher than etic cultural intelligence of the same expatriate at the same given time point.

\section{DISCUSSION AND CONCLUSION}

By narrowing the various gaps in our understanding of how epic and emic orientations affect various perspectives of cultural intelligence relate to more effective performance, both business development and individual career enhancement are likely to benefit. The research propositions offered in this paper, may help to further explain whether key orientation differences matter in cross-cultural transitions, and whether in understanding their impact, they benefit business development, the career enhancement of individual expatriates and the staffing strategies and practices pursued by Human Resource Management professionals more specifically in identifying and selecting those expatriates more likely to succeed and benefit from cross-border assignments. Individuals can also benefit by having a greater understanding of themselves; including the effects of cultural distance and direction of international assignments, thus work to address negative elements of personal differences while on a particular assignment. In addressing the subject matter of global professionals' cultural intelligence, this paper acknowledges the potential for the various perspectives and orientations in various cross-cultural business and social contexts. This can be further achieved by exploring and testing through empirical research the proposition raised in this paper.

\section{ACKNOWLEDGMENT}

Funding for this research was provided by National Natural Science Foundation of China under grants 71762033 and 41661029. The facilitation from international collaborative program and cooperation with Charles Sturt University in Australia is gratefully acknowledged. The assistance of Professor Mark Frost and Antony Bush are acknowledged.

\section{REFERENCES}

[1] Ang, S., Van Dyne, L., Koh, C. K. S., Ng, K. Y., Templer, K. J., Tay, C, and Chandrasekar, N. A. (2007). The measurement of cultural intelligence: 
Effects on cultural judgment and decision making, cultural adaptation, and task performance. Management and Organization Review, 3, 335-371.

[2] Bücker, J., Furrer, O., \& Lin, Y. (2011). Measuring Cultural Intelligence: a New Test of the CQ Scale. Academy of Management Annual Meeting.

[3] Berry, J. W., Segall, M. H., and Kagitcibasi, C. (Eds.). (1999). Handbook of cross-cultural psychology: Vol. 3. Social behaviour and applications. Boston: Allyn and Bacon.

[4] Hofstede, G. (2001). Culture's Consequences: Comparing Values, Behaviours, Institutions, and Organizations Across Nations, $2^{\text {nd }}$ edition, Sage Publications: Thousand Oaks, CA.

[5] Fang, T. (2005-2006). From "onion" to "ocean": Paradox and change in national cultures. International Studies of Management \& Organization, 35(4): 71-90.

[6] Fang, T. (2005-2006). From "onion" to "ocean": Paradox and change in national cultures. International Studies of Management \& Organization, 35(4): 71-90.

[7] Earley, P. C., and Ang, S. (2003). Cultural intelligence: Individual interactions across cultures.Palo Alto, Calif: Stanford University Press.

[8] Earley, P. C., and Gibson, C. B. (2002). Multinational work teams: A new perspective. Hillsdale,NJ: Lawrence Erlbaum.

[9] Sternberg, R. J., and Detterman, D. K. (1986). What is intelligence?: Contemporary viewpoints on its nature and definition. Norwood, NJ: Ablex.

[10] Fang, T. (2003). A critique of Hofstede's fifth national culture dimension International Journal of Cross Cultural Management, 3(3): 347-368.

[11] Fang, T. (2012). Yin Yang: A new perspective on culture. Management and Organization Review (Forthcoming).

[12] Fang, T. (2005-2006). From “onion" to "ocean": Paradox and change in national cultures. International Studies of Management \& Organization, 35(4): 71-90.

[13] Berry, J. W. (1999). Intercultural relations in plural societies. Canadian Psychology, 40, 12-21 